\title{
Publications
}

Tourism and the Consumption of Wildlife: Hunting, Shooting and Sport Fishing edited by Brent Lovelock (2008), xxii + 290 pp., Routledge, Abingdon, UK. ISBN 9780415403818 (hbk), GBP 85.00/ USD 170.00 .

This volume is one sign of the increasing academic interest in recreational hunting. It is part of a series on tourism and the focus on tourist hunters (understood as those who travel to fish, shoot or hunt in a region other than their own) means that it tackles only a subset of those who engage in recreational hunting. Of the 20 chapters, 16 are essentially case studies looking at specific instances of hunting; four of the cases are historical. The case study approach is one of the merits of the book. For an activity that is often controversial and where opposing sides often appeal to stereotypes, it is helpful to learn more about the diversity of the practice, including sea angling on the Namibian coast, Arab falconry, and polar bear hunting in Canada's Nunavut Territory. While there is a bias towards studies from Scandinavia, New Zealand and Australia, North America, and East and Southern Africa, the scope is broad enough to avoid charges of parochialism.

It is difficult to discuss this topic without saying something about terminology. Lovelock uses the term 'consumptive wildlife tourism' to denote the particular type of recreational hunting he is interested in. But besides conjuring up images of those restaurants in African capitals that entice tourists with the promise of a taste of the wild, it is not an expression that would be immediately recognised by practitioners. There are reasons to prefer the term 'tourist hunting' to describe the subject matter of this book, and the expression 'recreational hunting' to describe all practices that involve the killing of wildlife (including aquatic species) for recreation or fun. But no such preference is without drawbacks and the terminological diversity in this area ('safari hunting', 'trophy hunting', 'sport hunting', 'angling', 'sport fishing', etc.) is a reminder that each form of the practice is likely to possess unique characteristics.

The fact that this collection tackles recreational hunting from the perspective of tourism studies means that the authors make use of a range of social scientific theories and tools. For conservationists this is valuable, because tourist hunting is both a socio-economic phenomenon and one that has ecological impacts, and understanding the latter often requires that one also understand the former. In this regard the comparative study of sea angling and safari hunting in Namibia by Barnes \& Novella is exemplary. They use economic tools to shed light on the social and environmental impacts of these practices and to come up with policy-relevant conclusions. In a different way Gunnardotter's anthropological study of the interactions between tourist hunters and local hunters in Sweden is of considerable interest. The discussion of the tensions and accommodations between the two groups and the primary insight that an increase in tourist hunting strengthens the 'economic' character of the phenomenon (one reason why tourist hunting may encounter resistance from local hunters) is relevant in other parts of the world. Elsewhere, the application of social scientific theory offers fewer insights. Franklin writes of the 17 th century author Isaac Walton that 'nature for Walton provided a necessary counterbalance to the one-dimensionality of the capitalist social order.' But this is surely a thought that Walton could not have had, since the concept of a capitalist social order had not been invented at the time. Similarly, Preston-White's claims about the virtues of actor-network theory for understanding fly-fishing seem questionable.

Foote \& Wenzel, in their chapter on polar bear hunting in Nunavut, compare the ecological impacts of hunting with those of tourism based on polar bear watching. Not surprisingly, given the greater numbers involved and the higher degree of comfort required by the viewing tourists, the latter appear to have a much greater effect on the ecosystem. This leads the authors to query the distinction between consumptive and non-consumptive use. Another way of making this point is to say that we need to be clearer about the changes in ecosystems that different kinds of tourism bring about. There are worse things that can be done to an ecosystem than removing a number of individual animals. Dawson \& Lovelock also make a comparison between consumptive and non-consumptive tourism (comparing angling and kayaking) but their interest is with the different values of the two groups rather than the different impacts.

Lovelock rightly notes that the antihunting movement is the biggest threat to tourist hunting, although the threat is one that typically applies to other forms of recreational hunting as well. This movement has had some success in banning hunting, particularly in North America and the United Kingdom, although these successes have not been unqualified. In his chapter Campbell describes how the wildlife authorities in Manitoba use recreational hunting as a means of keeping the bear population below biological and social carrying capacities. In the face of objections to the hunt, they commissioned research on public opinion and targeted their message accordingly. The authorities were clear that their communications should be based on their own institutional mandate. This meant defending hunting on the grounds of its value as a management tool. To date, this defence has been successful.

In general, the debate about hunting would benefit from a more detailed understanding of all aspects of hunting, in its diverse forms, and greater clarity about the reasons that are advanced for and against it. This collection makes a contribution, from the perspective of tourism studies, to those goals, and is to be welcomed.

\section{BARNEY DICKSON}

Fauna \& Flora International, 4th Floor, Jupiter House, Station Road, Cambridge, CB1 2JD, UK E-mail barney.dickson@fauna-flora.org

The following titles have been received at the Editorial Office and may of interest to readers:

Tropical Conservation Biology by Navjot S. Sodhi, Barry W. Brook \& Corey J.A. Bradshaw (2007), xi + 332 pp., Blackwell, Oxford, UK. ISBN 9781405150736 (pbk), GBP 29.99.

The Ecology and Conservation of Asian Hornbills: Farmers of the Forest by Margaret F. Kinnaird and Timothy G. O'Brian (2008), xviii + 315 pp., The University of Chicago Press, Chicago, USA. ISBN 0226437124 (hbk), USD 45.00/GBP 23.50.

Problem-Solving in Conservation Biology and Wildlife Management, 2nd edition, by James P. Gibbs, Malcolm J. Hunter Jr and Eleanor J. Sterling (2008), xii + 328 pp., Blackwell, Oxford, UK. ISBN 9781405152877 (pbk), GBP 24.99. 